\title{
What makes industry-university collaboration succeed? A systematic review of the literature
}

\section{Robert Rybnicek $^{1}$ (D) Roland Königsgruber ${ }^{2}$}

Published online: 12 September 2018

(c) The Author(s) 2018

\begin{abstract}
Industry-university collaborations (IUCs) have received increased attention in management practice and research. The need for innovation in today's business environment and the ambition of policymakers to commercialize academic knowledge intensify this trend. However, although research has devoted considerable effort to finding the determinants of success for interfirm collaboration, much less is known about IUCs. This article presents the results of a systematic review of the literature on the collaboration between industry and universities. We perform an extensive analysis of research published on industry-university collaboration projects with the objective of distilling factors that influence the success of such collaborations. We propose a novel conceptual model, which synthesizes our empirical results, and use it to organize and categorize influencing factors and their interrelationship within the collaboration process. Based on our review of existing literature, we identify an agenda for future research in this domain.
\end{abstract}

Keywords Industry-university collaboration $\cdot$ Success $\cdot$ Systematic literature review

JEL Classification $\mathrm{I} 230 \cdot \mathrm{L} 300 \cdot \mathrm{O} 320 \cdot \mathrm{O} 380$

\section{Introduction}

Collaboration between firms has been an increasingly important issue for some decades and researchers have devoted considerable effort to finding the determinants of their success (e.g. Hillebrand and Biemans 2003; Parkhe 1993). A different form of collaboration with presumably different success factors is the one between industry

Robert Rybnicek

robert.rybnicek@uni-graz.at

1 Department of Corporate Leadership and Entrepreneurship, University of Graz, Elisabethstrasse 50b/II, $8010 \mathrm{Graz}$, Austria

2 SKEMA Business School - Université Côte d'Azur, Esplanade Mona Lisa, Paris La Défense Cedex, 92916 Courbevoie, France 
and universities. These actors pursue different objectives and face different constraints. This contrast potentially enhances the value of collaboration but it is also a source of complications. Results from the literature on interfirm collaboration do not necessarily carry over to this setting. In this paper, we investigate the success factors of collaboration between industry and universities.

Industry-university collaborations (IUCs) have a long tradition in several countries worldwide (Ankrah and AL-Tabbaa 2015) and universities play a crucial role in achieving economic growth in today's knowledge-based societies (Pinheiro et al. 2015a). The ambition of policymakers and universities to develop 'third missions' in addition to the two traditional core missions of research and teaching, and to commercialize academic knowledge, for instance through continuing education programmes, patenting, technology transfer offices, science parks or incubators has intensified the relevance of such collaborations (Marhl and Pausits 2011; Perkmann et al. 2013).

There are many reasons for IUCs: companies profit from highly qualified human resources such as researchers or students (Myoken 2013); they gain access to technology and knowledge (Barnes et al. 2002); and they can use expensive research infrastructure (Ankrah and AL-Tabbaa 2015). According to some estimates, up to 10 per cent of new products or processes are based on the contribution of academic research (Bekkers and Bodas Freitas 2008). Universities, in return, benefit from additional funding provided, from access to industry equipment or from licensing or patenting income (Barnes et al. 2002). In fact, collaboration with industry has become an inevitable part of university funding and the funds from international organizations and business enterprises for $\mathrm{R} \& \mathrm{D}$ in the higher education sector nowadays represent a 'significant source' in many countries (OECD 2015).

In light of these effects and financial relevance, it is important to ensure a successful management of IUCs to realize the advantages on both sides. While the number of research articles has increased in recent years, there is not yet a systematic overview of success factors that emerge from a detailed analysis of individual studies. Most studies do not directly address this question. Case studies, for example, generally only refer to individual lessons learned. Recent reviews summarizing the literature have mostly focused on other issues: for example, Perkmann et al. (2013) investigate how academic engagement differs from commercialization (in the sense of the exploitation of patented inventions), Schofield's (2013) systematic review of the literature is dedicated to success factors in the emerging market context, and while Ankrah and AL-Tabbaa (2015) also briefly discuss success factors, they focus primarily on organizational forms of IUCs, motivations for IUCs as well as their formation and operationalization. Therefore, our article aims to fill this gap by identifying relevant success factors, establishing a model for organizing them and providing practical recommendations and suggestions for future research. The strong focus on the core question 'What factors influence the success of a collaboration between industry and universities?' distinguishes our analysis from other reviews and articles, which mostly examine this question merely as a subtopic. Our approach allows a more thorough analysis of factors that facilitate or inhibit the IUCs' success, which goes beyond existing reviews such as those mentioned above. Our review adds to a better understanding of IUC success factors not only by summarizing the evidence 
but also by developing a conceptual model on the basis of a rigorous and transparent methodological approach, including the most recent research up to the year 2017.

The theoretical contribution of this article therefore consists of a novel conceptual model that we derive from our review of the literature and which we use to organize success factors and their interrelationship within the collaboration process. Our conceptual model hence synthesizes the current state of research regarding our research question. We draw on this model to discuss implications for management practice and propose a research agenda for further investigations. Based on the investigated literature we derive recommendations for the practical implementation of IUCs and furthermore identify a number of important gaps in the current literature. In particular, current literature provides some indication that a variety of parameters interfere with the factors we identify. The scale of the institutions, the phase of the collaboration project, the (scientific) discipline, or the organizational level (e.g., leaders, staff members) are potential moderators, which have not yet been investigated in depth. Our article is of interest to university members and corporate managers engaged in IUCs, to researchers in the field of R\&D management or higher education, and to policymakers.

The remainder of this article is structured as follows: In the next section, we summarize the method used for the selection and review of the literature. We explain our search strategy and illustrate the procedure. Following this, we present our results as we first describe our conceptual model and go on to report the synthesis of our findings. In the discussion, we then deliberate on implications of our study for practice and research.

\section{Methodology}

To answer our research question, a systematic review of the literature was conducted. We followed the principles of Denyer and Tranfield (2009) and Tranfield et al. (2003) who emphasize core principles that apply to systematic reviews of literature in the field of management and organization. Those principles allow the design of a replicable investigation and minimize any bias caused by the subjective assessment of different researchers (Tranfield et al. 2003).

The iterative review process consisted of a number of stages and is summarized in Fig. 1. Following Tranfield et al.'s (2003) principles, the process consisted of three main steps: (1) the locating of studies; (2) the study selection and evaluation; and (3) the analysis and synthesis.

\subsection{Locating of studies and study selection}

In the first step, the procedure started with a database search in EBSCO Business Source Premier, which includes 14,914 peer-reviewed journals (EBSCO 2016), and was performed in March 2016 and March 2018. The time frame for the database search was determined as 2000-2017 because there has been an increased interest in university cooperation over the last two decades (e.g., Ankrah and AL-Tabbaa 


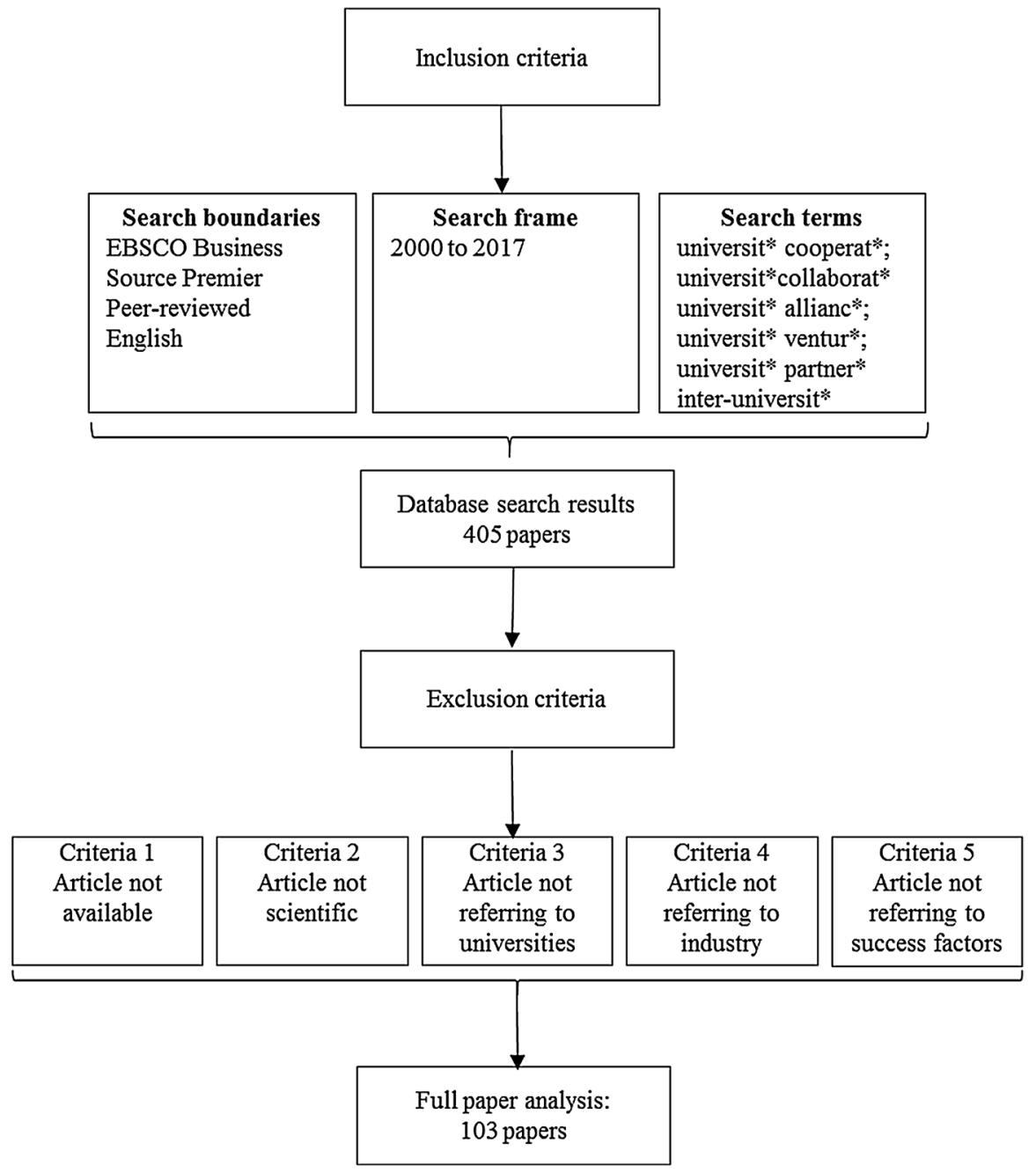

Fig. 1 Overview of the systematic review process

2015; Barnes et al. 2002; Perkmann et al. 2013) and a number of current concepts and strategies, such as the entrepreneurial university (Clark 2001; Etzkowitz 2003), the Triple Helix (Etzkowitz and Leydesdorff 2000), the mode 2 of knowledge production (Gibbons et al. 2002), and new public management (Leisytë and Kizniene 2006), stress the importance for collaboration and the need for third-party funding.

The search included only peer-reviewed papers published in English. Search terms applied for the database search were 'universit* cooperat*'; 'universit* collaborat*'; 'universit* allianc*'; 'inter-universit*'; 'universit* ventur*' and 'universit* partner*'. These terms are on the one hand broad enough to capture the most suitable articles and on the other sufficiently expressive to remove less 
suitable articles. Although some researchers use the terms 'university' and 'higher education' as a synonym, we decided to differentiate clearly between these two terms and searched solely for universities, as determined by our research question. Higher education systems differ greatly between countries and over time, which provokes essential problems in terms of comparability (OECD 2017). For instance, the OECD, which has long-standing institutional experience regarding international educational statistics, states that comparison issues remain a quintessential characteristic of the data. To illustrate, the OECD's (2017) report on the state of higher education devotes six entire pages to the challenges resulting from data acquisition and different definitions across countries. In order to ensure comparability, we therefore refrained from using a broader and ambiguous term but acknowledge that this may result in the exclusion of potentially relevant studies. The database search identified 461 papers. After eliminating duplicates, 405 papers remained. For administration of all articles, the reference management program Citavi 5 was used.

In the second step, we selected and evaluated the literature regarding our research question. As suggested by Tranfield et al. (2003), all of the 405 papers were evaluated by two reviewers who independently extracted data from these studies. Three research assistants were employed in this project to carry out these tasks. The assistants hold master-level diplomas and at the time of the study were employed in junior research positions at the university with which one of the authors is affiliated. They have research experience and engaged in methodological discussions with the authors. The iterative process of analysis and discussion was deliberately designed to achieve high inter-rater agreement. The definition of the terms, the guidelines for coding, and specifications for interpretation were elaborated and decided by the authors. Decisions on adaptations were the sole responsibility of the authors. The findings and interpretation of the reviewers were compared to minimize errors, resolve differences and produce a more robust data set (Tranfield et al. 2003). We developed a set of five exclusion criteria to allow the assessment of each study. Articles not meeting these criteria were excluded. First, we excluded articles from the review in the rare case of the document not being accessible. The second exclusion criterion concerned the scientific approach of the papers-we excluded, for example, book reviews or any kind of non-scientific articles. Using the third and fourth exclusion criteria, we eliminated articles that slipped into our search results but did not address both universities (criteria 3 ) and industry (criteria 4). The fifth exclusion criterion was whether a paper explicitly addressed factors that influence the success of a collaboration. As recommended by Boaz and Ashby (2003) and Pawson (2006) we decided to include a wide range of studies in our examination in order to capture anything that was new to our understanding of those factors. To ensure this, the exclusion of articles and the in-depth analysis were designed as an iterative process. Hence, at this step some articles remained in the investigation but were excluded later when the in-depth analysis revealed that these articles ultimately did not deal with success factors. For the assessment and evaluation of articles, the above-mentioned guidance for interpretation was applied. In the end, the exclusion process resulted in a total of 103 academic papers. 


\subsection{Analysis and synthesis}

In the third step, the research assistants used data extraction sheets independently from one another in order to analyse all articles identified. These data extraction sheets were implemented in Microsoft Access 2016 to allow a high degree of transparency and to minimize input data errors. The research assistants continually compared their results; in case of disagreement, the opinion of an additional reviewer was decisive. Each data extraction sheet consisted of the following elements: bibliographic data, research aim, method, type of collaboration, country, university, results, limitations and factors that influence the success of an IUC.

The aim of the present study was to determine factors influencing the success of an IUC. In that regard, we faced a trade-off between imposing a homogeneous definition of success, which would improve comparability but potentially violate the 'fit' between the aim of the original study and its method (a key quality criterion of research identified, e.g., by Boaz and Ashby 2003), or taking the original papers' definition of success to uphold that fit. We only examined papers that explicitly considered factors that facilitate or inhibit the IUCs' success as part of our inclusion and exclusion criteria. We hence opted for the option to keep the original papers' definition of success to the detriment of imposing a homogeneous definition.

We followed an iterative process to derive those factors. In this process, deductive and inductive methods were combined. We started with factors facilitating or impeding IUCs that have been suggested by other authors, e.g. Ankrah and AL-Tabbaa (2015), who provide a short list of factors. We also drew on related literature that refers to other sorts of collaboration-for instance, Mattessich et al. (2004), who investigated collaborations formed by human service, government, and other nonprofit agencies. We used this initial list of factors and iteratively adjusted it, adopting, adding, and eliminating individual factors in a process of refinement involving continual discussions between the authors and the research assistants working on the data. In the process of the analysis, a guidance to interpretation was developed, which was used to determine whether a paper's content could be subsumed under a particular factor. This led to a modification of some factors and to the addition and deletion of others. As suggested by Denyer and Tranfield (2009), we then crosstabulated the investigated studies to identify key issues and to see whether there is one single foundation or whether there are contending or complementary findings. To be specific, we first counted how often a factor was mentioned. Then all relevant text passages were copied in a single spreadsheet table, which we used to examine whether certain subjects were mentioned repeatedly. In our quantitative analyses we investigated regularities and discrepancies and in our qualitative analyses we analysed and explored the studies for analogous or different meanings (Denyer and Tranfield 2009).

Subsequently, we synthesized our findings and inductively developed a conceptual model. Categories developed in Perkmann et al. (2013) were taken as a starting point. We classified factors identified in the process above into individual categories and adapted the category system to fit our research question and the factors identified. During the development of this model, we noticed that authors repeatedly mentioned a number of circumstances as potentially affecting the relation between 


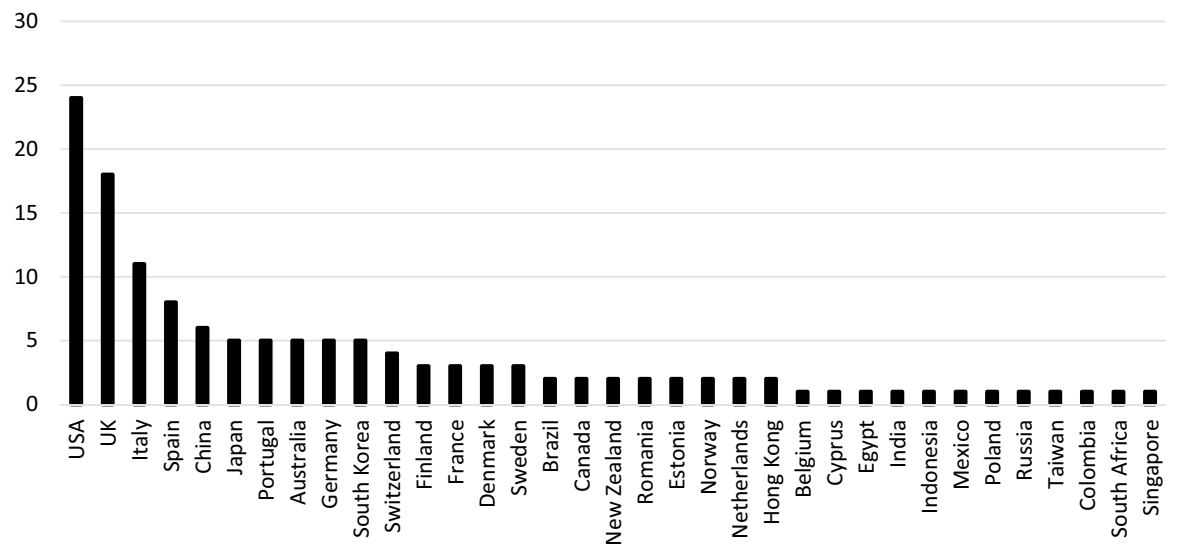

Fig. 2 Country of authors

the factors we had identified and the success of IUCs. We call these circumstances 'moderators'. In a final step, we added our implications for managerial practice and completed the model with the identified moderators that might interfere with our success factors. More information is provided in Sect. 4.2.

\subsection{Descriptive data}

The research yielded 103 suitable articles, which corresponded to our inclusion criteria. Of these, 56 included quantitative and 47 qualitative analyses, 26 of which were case studies. Furthermore, 12 literature reviews were analysed. (We note that there were also papers with mixed methodology, which were assigned to more than one category.) The high number of case studies could be an indication that research regarding IUCs is still explorative to a great extent.

The analysed papers were published in 64 different journals; about two-thirds of the papers were published in journals with an impact factor (IF). In Appendix an overview of the journals, the number of articles published in these journals and their impact factors is provided. The key publication outlets are Research Policy (9 articles), $R \& D$ Management (5), International Journal of Innovation Management (4) and Journal of Product Innovation Management (3), Management Decision (3), Small Business Economics (3), Technology Analysis \& Strategic Management (3), Technovation (3). The scope of the journals indicates that our research topic has been studied from at least three different perspectives. The first perspective refers to research administration and research policy, the second perspective is aimed at the innovation process and innovation management and the third perspective focuses on management and business.

As depicted in Fig. 2, most articles are from authors or co-authors from the United States (24), followed by the United Kingdom (18), Italy (11) and Spain (8). A total of 26 articles have authors from more than one country and in 60 per cent 


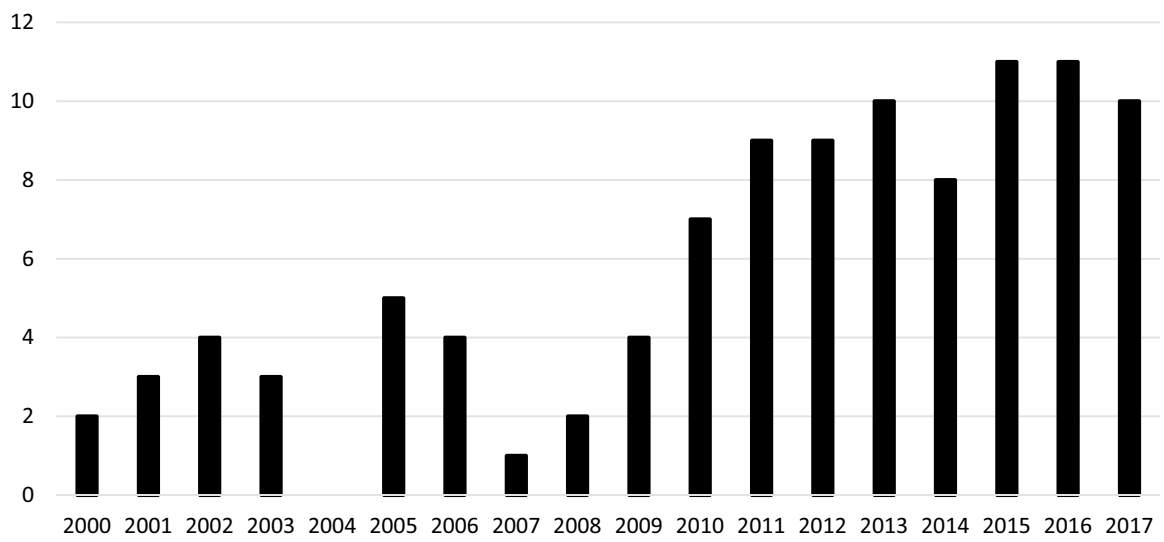

Fig. 3 Number of publications per year

at least one author from Europe contributed to the paper. Authors were assigned to countries by their affiliation.

Figure 3 shows the number of publications per year. The number of papers has increased over the last decade and has remained stable at a high level since 2015, which indicates the rising relevance of the investigated topic in recent years.

\section{Results}

\subsection{Conceptual model}

Based on the insights gained from the review, we derived a conceptual model, which we depict in Fig. 4. During the development of our model, we had to make some fundamental decisions to reduce complexity. The main idea that guided these decisions was to relate the factors to the collaboration process. Some factors might address different facets within this process and, consequently, their assignment is not absolutely clear. In those cases we closely analysed which of the identified issues discussed in the literature are predominantly relevant in terms of our research question. The conceptual model contains three distinct elements:

1. Generic collaboration: According to Bryson et al. (2006) a cross-sector collaboration is defined as the linking of organizations in two or more sectors to achieve jointly an outcome that could not be achieved otherwise. Hence, this simplified presentation comprises the organizations (industry partner and university partner), the linking between those organizations and the results.

2. Factors (see the coloured headings in Fig. 4): We organized the factors identified around this process and derived four distinct, overarching categories. Firstly, there are the institutional factors, which refer to the participating institutions; secondly, there are the relationship factors, which refer to the linking between those partners; thirdly, we have the output factors, which refer to the desired results of 


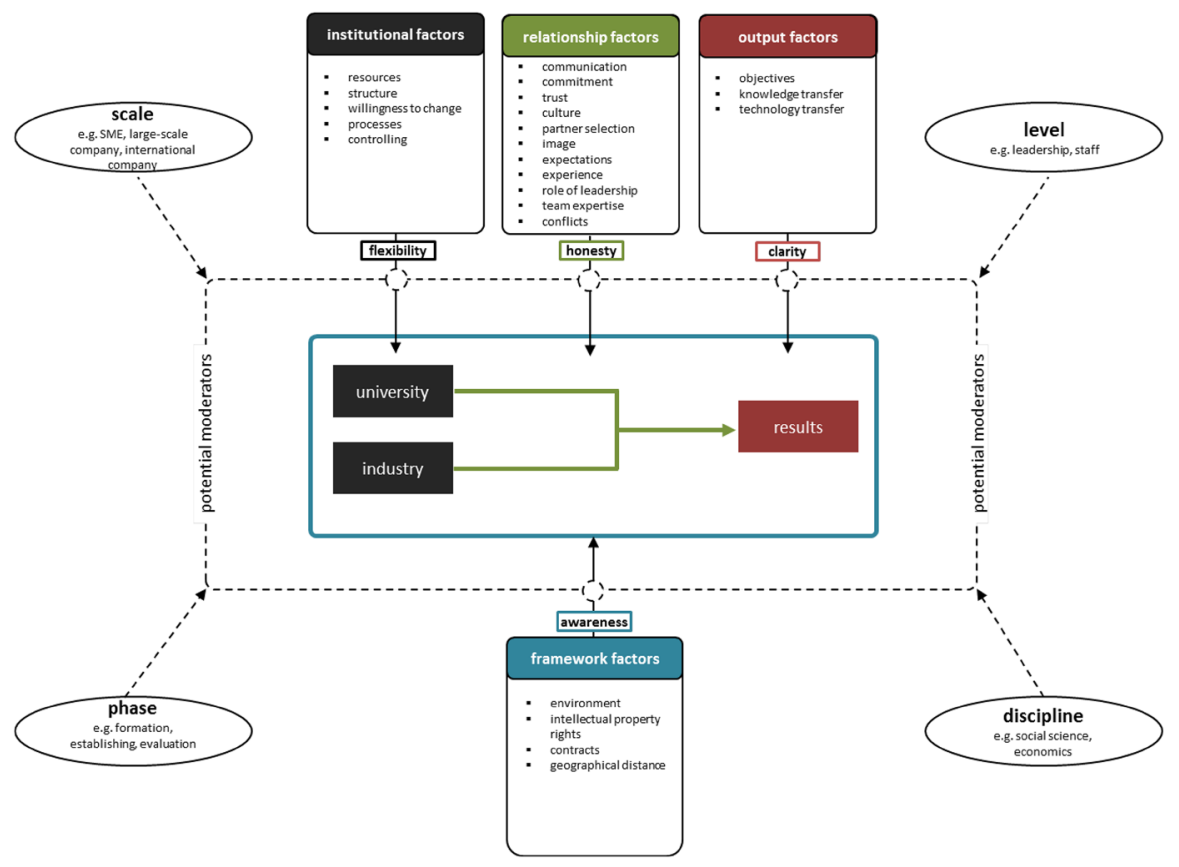

Fig. 4 Conceptual model

the collaboration; and fourthly, there are the framework factors, which refer to environmental aspects. These findings are presented in the Sects. 3.2, 3.3, 3.4 and 3.5 below.

3. Moderators (see the ellipses in Fig. 4): These represent circumstances of IUCs that might have an impact on the way individual factors affect the collaboration. The literature provides various hints that the phase of a collaboration process, the scale of the partners, the organizational level or the (scientific) discipline might interfere with our factors, but as yet this has not been investigated. We hence consider them to be particularly promising avenues for future research and discuss them in Sect. 4.2 under the heading 'Implications for future research'.

For illustrative purposes, we have also included one core recommendation for managerial practice stemming from each category of factors in Fig. 4. We describe the recommendations in more detail in Sect. 4.1.

Overall, Fig. 4 provides an overview of the current state of research, visualizes relationships between the identified factors and a generic collaboration process, allows the identification of future research activities and depicts issues for the practical implementation of successful IUCs. In the subsequent sections, we synthesize the main results of our study. 


\subsection{Institutional factors}

Resources play an important role in the successful implementation of IUCs. In general, the quality and the utility of a collaboration is strongly dependent on the resources a partner can offer. The need for certain kinds of resources limits the number of potential partners considerably (Ferru 2010). In our analysis, we identified finance, time, staff and equipment as critical resources. For successful collaboration, the discussed issues range from the provision of resources, to the accuracy of planning and the commitment of partners (e.g., Arvanitis et al. 2008; Schofield 2013). Potential barriers are, for example, the different understanding of time issues (Goduscheit and Knudsen 2015), the short-term orientation of industry research (Muscio and Vallanti 2014) or unrealistic expectations of the partners (Barnes et al. 2002). Good timing is also critical for successful IUCs, however, while industry requests constant availability, universities have restrictions in the context of their semester structure (Wu 2017). Furthermore, to facilitate a successful collaboration, access to highly qualified human resources (Myoken 2013), to infrastructure such as libraries and lab space (Boardman and Bozeman 2015) or to technical equipment (Arvanitis et al. 2008) is important. However, such expensive infrastructure is often obtained for internal use. A potential way to gain mutual access to it are shared-use equipment arrangements (Bychkova 2016).

A further institutional factor is related to structure. In this regard, the different background of companies and universities is especially challenging. For example, the bureaucracy, the complex structure and the inflexibility of universities (Schofield 2013) can hinder the success of IUCs because universities' rigid framework is opposed to the flat hierarchy of company management (Boardman and Bozeman 2015; Schofield 2013). Bureaucratic organizations and unclear responsibilities are therefore major barriers to a successful partnership. For a fruitful project, for instance, researchers have to feel responsible for it (Franco and Haase 2015). Further issues refer to the lack of administrative support (Franco and Haase 2015) or to decision-making differences (Reeve and Gallacher 2005). Project management can help here to enhance the coordination and communication between partners (Rajalo and Vadi 2017). Positive effects are also reported for the adoption of formal rules (Muscio and Vallanti 2014) or when responsibilities and roles are clarified right from the beginning of a partnership (Barnes et al. 2002). The development of mechanisms and processes, including the roles in the teams and a mutual terminology, can improve the collaboration (Canhoto et al. 2016).

There is also some evidence that willingness to change is another salient success factor. That means, for instance, adapting to different circumstances and cultures (Logar et al. 2001), being open to listening (Ryan 2007, 2009) and managing corporate changes (Barnes et al. 2002). The ability of partners to learn about and understand one another is essential for a successful collaboration (Hadjimanolis 2006). However, partners need to have time for this learning process in order to find the best way to collaborate (Canhoto et al. 2016). Both companies and universities will benefit when they work together closely and use each other's experience and feedback for further improvements (Ryan 2009). 


\subsection{Relationship factors}

The impact of communication has been extensively addressed in the investigated literature. With respect to communication, the frequency of communication is vital to create a shared understanding (Hong et al. 2010; Lee 2011). Good personal relationships are the basis to enabling vital linkages between companies and universities (Barnes et al. 2002; Collier et al. 2011). In this regard, contacts and actions should not only include management level but must be on the operational level too (Wu 2017). This includes regular interaction, continuous feedback, mutual exchange of information and updating partners about incidents or new activities. Furthermore, communication through a variety of channels, such as e-mails, regular meetings or face-to-face communication is advantageous (Clauss and Kesting 2017; Hong et al. 2010), although partners need to select those channels carefully since the lack of efficient communication channels is also considered a main barrier in partnerships (Guan et al. 2005). A reciprocal communication (regularly, timely, adequately and accurately) is also beneficial to establish positive expectations about the future behaviour of partners, particularly when the partnership is new (Bstieler et al. 2017). Another requirement for a successful collaboration is to find an appropriate 'language' suitable for both partners, because IUCs are often affected by the use of different dictions and styles in the academic and business environments (Baba et al. 2010; Gawel 2014).

A large proportion of studies discusses the importance of commitment. Commitment refers to the questions of how much a person identifies with the collaboration and its goals, how loyal this person is to this collaboration and whether they are willing to put sufficient effort into it (based on Porter and Smith 1970 as cited in Mowday et al. 1979). The existence of a mutual commitment supports industry-university partnerships (Attia 2015), and the commitment of the top management in particular is a crucial factor in that regard (Ankrah and AL-Tabbaa 2015) because partners (and their leaders) will not share resources when they are not committed to a collaboration. There is also evidence that the attitude to IUCs affects commitment. For example, researchers are more likely to be committed to a collaboration with industry partners in cases where they have a positive attitude towards collaboration (Sellenthin 2011).

Many authors consider trust as another important relationship factor in fostering a collaboration between industry and universities (e.g., Attia 2015; Canhoto et al. 2016). Mistrust, in turn, influences the information flow and can lead to a departure from the original focus of a collaboration project (Barnes et al. 2002). Therefore, partners need to spend sufficient time on establishing mutual trust (Gawel 2014). Past experiences in working together, historical experiences in collaborating, or undertaking smaller projects in order to maintain personal contacts at the beginning of a new partnership can facilitate trust (Barnes et al. 2002). There is also evidence that trust can be maintained and reinforced by adopting similar operating and decision-making styles (Bstieler et al. 2017). Ambiguous experiences regarding the relationship between trust and the type of communication are reported by Canhoto et al. (2016). While some interviewees stated that face-to-face communication is still essential for trust building, others indicated that they do not need to meet in person to establish trust. Additionally, the leadership in IUCs can set an example and send positive signals for building trust (Barnes et al. 2002). Furthermore, strong 
ties between partners, a good reputation and contractual safeguards to reduce uncertainty usually have positive effects on trust (Hemmert et al. 2014). However, the intensive use of contractual safeguards can also weaken each other's trust in cases where there are already strong ties between partners (Hemmert et al. 2014). The role of trust might also vary with regard to the IUCs' quality. In excellent or promising collaborations, partners experience trust as a 'glue' or supportive factor, while in modest collaborations the lack of trust is often mentioned by partners as negatively affecting the collaboration project (Rajalo and Vadi 2017).

From our analysis, it is evident that culture plays a crucial role in IUCs. Culture refers to the mutual understanding within an organization about how members should perceive, think and feel about problems and challenges (Schein 2004). Partners have to handle the cultural gap between industry and universities carefully and must achieve a balance between each partner's requirements and priorities (Barnes et al. 2002). In this context, it is important to acknowledge that each organization or department has its own terminology and mode of operation and partners must identify these discrepancies and must establish a common language early in the project (Canhoto et al. 2016). Even trivial issues like meetings can be challenging when the participating persons have different ideas about the procedures or consequences of those meetings (Starbuck 2001). An entirely different stream of research refers to national differences-for instance, different trust-building measures, different time frames or different interpretations of contracts (e.g., Hemmert et al. 2014).

\subsection{Output factors}

A factor that has received much scholarly attention is objectives. Objectives refer to the strategy, visions, goals, plans or expected outcomes of a collaboration. One of the most discussed subjects is the compatibility of goals. A lack of compatibility can endanger the achievement of desired outcomes (Henderson et al. 2006). For example, universities wish to publish findings whereas companies seek to withhold them from competitors (Newberg and Dunn 2002). Similar results are provided by Lai and $\mathrm{Lu}$ (2016) who state that universities and companies are looking for different outcomes and it is hence important to understand the other's interests and to create a win-win situation in which the benefits are correctly balanced. It appears to be essential that the partners establish a shared understanding of the objectives, agree upon achievable project goals and develop an exact strategy plan throughout the whole collaboration (Hong et al. 2010). A proper partner selection process ahead of a collaboration, in order to find the right partner, is advisable. In this regard, it is necessary to be sure of one's own needs and requirements. Only then can the search for an adequate partner with concordant interests and goals begin (Arvanitis et al. 2008). Appropriate search strategies can help to find partners that fit and that match each other's expectations. Barnes et al. (2002) recommend a partner evaluation method with specific criteria. Furthermore, partners often have unrealistic expectations regarding the outcome of a collaboration or they have a different sense of urgency (Attia 2015). This lack of understanding of each other's work practices can lead to doubts about the priorities of both partners (Attia 2015). 
There is also a lot of evidence that an effective knowledge and technology transfer is important for a successful collaboration (Philbin 2010). An intense transfer can foster innovation performance (MingJi and Ping 2014), improve the technology novelty (Guan et al. 2005) or enhance product development (George et al. 2002). This holds true particularly for knowledge-intensive business services (Fernandes and Ferreira 2013). But there are significant barriers to knowledge transfer-for example, differences in the knowledge base (Hong et al. 2010), cultural factors (de Medeiros et al. 2012) or limited knowledge transfer experience (Schofield 2013). Further aspects that can facilitate or impede transfer activities are the nature of the knowledge and technology (Ankrah and AL-Tabbaa 2015) and the explicitness of the knowledge (Santoro and Bierly 2006; Xu et al. 2014). As knowledge and technology transfer is also a question of motivation and strategy (Flores et al. 2009), policies and appropriate incentives can foster transfer activities in such collaborations (Schofield 2013). Interestingly, universities and companies might have different roles in knowledge transfers. While university scientists often initiate knowledge transfer, companies take on more managerial roles afterwards (Goel et al. 2017). However, as stated by Goel et al. (2017), a technology transfer system that solely relies on this allocation of roles may not be sustainable.

\subsection{Framework factors}

According to the literature, the environment can also have an impact on IUCs. It refers, for instance, to governmental support, legal restrictions or the market environment. The government is an influential power that can either enhance or harm collaboration (Kozlinska 2012). On the one hand, tax incentives (Bodas Freitas et al. 2013a), public funding (e.g., Flores et al. 2009; Piva and Rossi-Lamastra 2013) or the governmental network (Rampersad 2015) can facilitate IUCs. On the other hand, legal restrictions and regulations (Arvanitis et al. 2008; Attia 2015; Hadjimanolis 2006) or the lack of regional support structures (Şerbănică 2011) can have a negative impact on collaboration. Generally, governmental support is often necessary to establish a collaboration between universities and industry work (e.g., Collier et al. 2011; de Medeiros et al. 2012; Hemmert et al. 2014; Muscio and Vallanti 2014; Myoken 2013; Newberg and Dunn 2002; Schofield 2013; Sohal 2013). Further environmental success factors refer, for instance, to the market potential of the research results (Ankrah and AL-Tabbaa 2015; Barnes et al. 2002; Guan et al. 2005; Hadjimanolis 2006) or to market uncertainties (Hemmert et al. 2014).

The next two factors we identified within our literature review refer to the legal aspects of IUC collaborations and are about contracts and intellectual property rights (IPRs). Contracts detailing the arrangement, roles and responsibilities reduce the possibility of later disputes (Ankrah and AL-Tabbaa 2015; Barnes et al. 2002; Lee 2011; Ryan 2009), can help to establish trust (Hemmert et al. 2014) and are necessary to verify whether objectives have been met by the partners (Xu et al. 2014). Formal agreements are especially advisable in complex collaboration projects (Starbuck 2001) or to ensure mutual access to expensive infrastructure (Bychkova 2016). Confidentiality and non-disclosure agreements play an important role in IUC projects and the setting up of proper agreements is an important task for the participating partners 
(Attia 2015; Bruneel et al. 2010; Perkmann and Salter 2012; Perkmann and Schildt 2015; Rampersad 2015). With respect to patents or other IPRs, problems and conflicts can arise regarding the project ownership or royalty payments (Arvanitis et al. 2008; Attia 2015; Bodas Freitas et al. 2013a; Bruneel et al. 2010; Guan et al. 2005; Muscio 2013; Perkmann et al. 2011; Piva and Rossi-Lamastra 2013; Schofield 2013).

Finally, there is evidence that geographical distance is another relevant success factor. A suitable geographical distance enhances the access to highly qualified facilities and human resources (Myoken 2013) and makes the collaboration between industry and university partners more likely (D'Este et al. 2012). Even today, face-to-face interaction is preferred to other forms of communication and can therefore be a motivation for engaging in a collaboration with close geographical proximity (Indarti and Wahid 2013). However, there is evidence that the importance of geographical proximity diminishes when there are employee-driven relations (e.g., the graduation of employees or managers from a certain university) between the university and the company (Drejer and Ostergaard 2017). Despite these results, Drejer and Ostergaard (2017) conclude that to a certain extent geographical proximity matters for IUCs regardless of these relationships or the university's quality and ranking position. Interestingly, in this context we have also to distinguish between different kinds of knowledge: companies collaborating with universities for consulting issues searched for partners in the same region, while those collaborating for $\mathrm{R} \& \mathrm{D}$ or technical advice searched for partners outside their region (Isabel Maria et al. 2014). Although most evidence is in favour of a short distance between collaborating partners, there are also results to the contrary, which indicate that successful IUCs tend to occur particularly between partners who are geographically at some distance from one another (Petruzzelli 2011).

\section{Discussion and implications}

\subsection{Implications for practitioners}

In this section, we discuss and summarize recommendations for management practice derived from the investigated literature, which are of importance for those parties who are or will be engaged in IUCs or who are responsible for their implementation. In order to derive these key recommendations, we proceeded as follows: We started by establishing an extensive table where we extracted the practical recommendations from individual articles. To do this, we excerpted or paraphrased recommendations from a close reading of each article. Subsequently, we categorized these recommendations according to our conceptual model and assigned them individually to a factor we had identified. Finally, we iteratively clustered the recommendations to determine superordinate recommendations. In this final step, we identified one overarching recommendation per category of factors, which we included in the depiction of the conceptual model in Fig. 4.

Before proposing one main advice for each category, we note that the initial decisions of a collaboration are whether is it reasonable to collaborate and if so with whom. With the prospect of all the possible advantages of an IUC, the temptation to enter into an overhasty collaboration without sufficient consideration of the above-mentioned 
issues is very high. Universities' third missions virtually force them into an exchange with industry and, in turn, the prospect of a 'scientific touch' might be seductive to some companies. However, the wrong partner could even increase costs if the partners' objectives do not align, if there are controversial views on certain aspects or if problems occur in working together (Banal-Estañol et al. 2013). Collaboration for collaboration's sake or because of internal or external pressure should be avoided at all cost. Below, we identify one key aspect per category of factors that appears essential to us based on the review of the literature presented in this article.

- Regarding the institutional factors, we advise flexibility. That means, for instance, to be flexible regarding one's own priorities as the partner might have others (Poston and Richardson 2011), to adopt formal rules where necessary and to compromise where appropriate (Muscio and Vallanti 2014), to be openminded and to seize chances (Barnes et al. 2002; Ryan 2007). It is important to understand and accept cultural differences and to not impose one's own conventions and approaches on the partner (Barnes et al. 2002; Starbuck 2001). It has been shown to be beneficial to create collective goals and to share the same visions and interests (Hong and Su 2013). Altogether, management and management processes need to be flexible enough to cope with instability and change (Barnes et al. 2002) as well as with the diverse interests of the partners.

- Regarding the relationship between both partners, we advise paying attention to honesty. That means, treating the partner fairly, communicating openly and honestly, and informing partners of current developments immediately in order to foster trust (Barnes et al. 2002). We further recommend commitment to promises made (Sellenthin 2011) and transparency and honesty regarding goals, IPR policies or knowledge transfer (Bstieler et al. 2015; Santoro and Bierly 2006). Trust and reputation play an important role when partners share one of their most valuable assets - their knowledge. Therefore, trust and trust building is an important issue (Bstieler et al. 2015; Hemmert et al. 2014) and honesty is a fundamental basis of this.

- Regarding the output factors, our advice is for clarity. That means, for example, having clear aims, planning as realistically as possible, agreeing on responsibilities, specifying the extent of the contribution of each partner and defining roles right at the beginning (Barnes et al. 2002; Franco and Haase 2015). Articles we reviewed also recommend being clear about expectations (Barnes et al. 2002) regarding IPR policies (Starbuck 2001), ownership and patent earnings (Barnes et al. 2002; Bruneel et al. 2010) or about the exploitation of project results (Newberg and Dunn 2002). In this context it is essential to take enough time to understand the partner's interests, to ask questions if necessary, to discuss purposes and visions and eventually to negotiate these (Borgia et al. 2011; Ryan 2009). Concrete agreements and contractual safeguards might help in this regard (Hemmert et al. 2014). Summing up, while the different background of the two partners may lead to temptations to remain vague in the conception of the IUC, in the long term a collaboration is more likely to succeed if the main points are clarified between the partners.

- Regarding the framework factors we particularly advise partners raising awareness of current economic, legal, political or social developments. These developments have a great impact on collaboration and therefore should be neither underesti- 
mated nor neglected. This implies keeping up to date with them and being aware of their influence on companies and universities-for example, observing and exploiting opportunities for public funding (Flores et al. 2009; Piva and Rossi-Lamastra 2013) or watching out for the possibility of (tax) incentives for IUCs (Bodas Freitas et al. 2013b; Myoken 2013). Furthermore, it includes monitoring changes in the market environment (Hadjimanolis 2006) and being aware of corporate instability (Barnes et al. 2002). It also means on a more general level, analysing the wealth, the innovation intensity or the employment market of a region (Berbegal-Mirabent et al. 2015). To sum up, for the establishment of a successful IUC it is advisable to study the environment in which the collaboration is to take place, to be aware of current developments or future changes and to monitor environmental influences.

\subsection{Implications for future research}

Our review of the literature shows that the study of factors influencing the success of an IUC requires further attention. During the analysis, some more aspects that might interfere with our factors were identified but their actual effect is unclear. We call these aspects moderators as they potentially influence the impact of our factors on the probabilities of a collaboration project being successful. We repeatedly noted that authors mention these aspects in their research articles but do not study them in great depth. Researchers thus recognized their importance but apparently did not investigate them as they were only recognized ex post facto. Future research will be necessary to examine these issues.

\subsubsection{Different phases}

Some studies indicate that the importance of the investigated factors varies over the course of an IUC. During the formation of a collaboration, for example, regular meetings and frequent communication (Hong et al. 2010), clearly defined responsibilities (Barnes et al. 2002) and/or a considerable time commitment to share ideas (Poston and Richardson 2011) are necessary. As the collaboration progresses other aspects may become important, e.g., flexibility and the ability to learn and understand one another (Hadjimanolis 2006) and/or the existence of mutual trust (Attia 2015). And, again, in longterm collaborations there will possibly be other factors that are particularly relevant.

Previous studies remain vague about these deliberations and refer more to personal experiences or lessons learned. Nevertheless, statements like 'especially at the beginning' point toward differences regarding the phases of a collaboration. While conducting our review, this idea was reinforced and there are logical reasons for an approach that additionally considers different phases. Challenges regarding the partner evaluation or the accurate estimation of costs and revenues occur naturally at the beginning of the collaboration, while delays and postponements or the acquiring of highly qualified human resources might be important during the actual process of collaboration.

There already exist some more recent studies that investigate selected factors across different phases like Plewa et al. (2013a) or Plewa et al. (2013b) with regard to 
communication and trust. However, for most success factors it remains unclear to what extent their impact varies over the course of time. Therefore, future research should investigate the relationship between different factors and different phases of a collaboration project, because the likelihood of a successful collaboration will increase when the participating partners know what they should keep their eye on during the project.

\subsubsection{Different scales}

The existing literature does not really discuss differences regarding the scale of companies or universities, although there is some relevant research that focuses specifically on small and medium-sized enterprises (SMEs) (e.g. Collier et al. 2011, Karlson and Callagher 2012 and Goduscheit and Knudsen 2015).

We can say that SMEs in general have different requirements and possibilities to those of large-scale firms and therefore it might also be that for collaboration with SMEs other factors are more relevant than those for a collaboration with larger companies. When reviewing the literature this assumption became even more evident. SMEs often do not come into contact with researchers and have problems gaining access to information and knowledge from universities (Howells et al. 2012). They may find the search and scanning costs for an appropriate partner too high (Howells et al. 2012), a problem that most certainly will not occur for financially strong and well-known (international) players. Also, corporate instability is more often a concern for SMEs since they are particularly vulnerable to closure, takeover or changes in business strategy (Barnes et al. 2002). Hence, when collaborating with SMEs it might be more important to watch out for environmental changes. Further important issues for a collaboration with SMEs refer to the motives for partner selection (Karlson and Callagher 2012), to the organizational culture (e.g., levels of formality or risk perception; Collier et al. 2011) or to values and time horizons (Hadjimanolis 2006). Furthermore, SMEs are known to participate avidly in EU calls that provide funding for IUCs (Piva and Rossi-Lamastra 2013), which suggests that governmental funding plays a special role in such collaboration projects.

The financial power, the bargaining strength, the potential endurance and the possibility to handle setbacks adequately might vary between companies of different scale. It would appear that, reported success factors, such as the financing of a collaboration project, culture and trust, the mutual use of resources like equipment, infrastructure or the exchange of qualified staff, are also influenced by the scale of a company and might differ between SMEs and larger companies. Future investigation in this regard is required to allow further conclusions to be reached. This topic is becoming increasingly important because today IUCs are not only a matter for international firms but also concern enterprises of all sizes, beginning with start-ups and other entrepreneurial activities with high innovation potential.

\subsubsection{Different organizational levels}

We also found some evidence that the affiliation to different organizational levels might interfere with some of our factors. Some aspects are more important for the leadership or management of an institution, while others primarily concern researchers or staff members. We note that most IUCs are operationalized at the level of 
individual academic departments rather than the level of a school or the entire university. This often necessitates the existence of individual 'champions' who help bridge the gap between different organizational levels within the university and between the university and its industrial partner (e.g., Santoro and Chakrabarti 2002). The role of such champions in fostering trust between partners appears to be particularly important in settings where there is little experience with IUC (Hemmert et al. 2014).

Leaders, for example, can foster trust, conduct an honest communication and have a strong role model effect (Barnes et al. 2002). The commitment and support of leaders is known to facilitate or impede collaboration on all levels (Ankrah and AL-Tabbaa 2015; Bergner et al. 2010). Many tasks are often the responsibility of leaders and managers: for instance, the distribution of resources or goal setting or the establishment of incentives or rules to motivate members to share their knowledge (Schofield 2013). Staff members, however, are responsible for maintaining frequent communication via multiple communication channels (e.g., e-mail, telephone, meetings) between the workforce (Hong et al. 2010), or have to find a mutual language between academic and business staff (Baba et al. 2010; Gawel 2014). Further aspects refer to the attitude and commitment of staff members towards collaboration (Sellenthin 2011) or interpersonal links and networks (Collier et al. 2011). And some other aspects might be considered on an institutional level—for instance, cultural differences between organizations (Barnes et al. 2002; Starbuck 2001).

Altogether, the investigated literature supports the consideration that some of our factors interfere with the organizational level of individuals; but these studies do not investigate this question specifically and remain rather speculative on this point. It seems worth taking a closer look at these differences, because for a successful IUC individuals at all levels have to contribute. Hence, it will be advantageous to have a better understanding of which factors are relevant for leaders and managers and which for staff members, such as experts, researchers and administrators. The literature on power in organizations (Pfeffer 1981), and in particular the role of champions in using their power to highlight the value of collaboration (Santoro and Chakrabarti 2002), may provide a relevant theoretical basis. ${ }^{1}$

\subsubsection{Different disciplines}

The last potential moderator refers to (scientific) disciplines. There are good reasons to suggest that scientific disciplines might moderate the relevance of some of our identified factors.

Scientific disciplines have different conventions and cultures, they use different methods and instruments and some of them have a strong focus on applied research or are more open to the needs of industry. The investigated articles do not examine this question, but, for example, with respect to academic R\&D collaboration projects Niedergassel and Leker (2011) conclude in their study that other scientific disciplines could have yielded different results. In that vein, Cummings and Kiesler (2007) state

\footnotetext{
${ }^{1}$ We thank the reviewer for pointing out this literature.
} 
in their investigation regarding multi-university collaborations that they cannot guarantee the generalizability of their results when it comes to other disciplines.

If these assumptions hold true for academic collaborations, it is reasonable that the scientific field might also impact IUCs. For instance, trust-building measures between industry and university partners might be more important for a project involving humanists than economists, or access to research equipment and infrastructure might be particularly relevant for natural scientists. Hence, we assume that the (scientific) discipline is a potential moderator for our success factors and future research should investigate its specific role in that regard.

Finally, it is interesting to note that the articles we reviewed hardly ever addressed the subject of risk management, a formal process of 'coordinated activities to direct and control an organization with regard to risk' (International Organization for Standardization 2018). This is all the more surprising as today risk management should be an indispensable part of the governance and leadership of an organization and should be included in all activities associated with an organization and its stakeholders (International Organization for Standardization 2018). In other cross-sector collaborations risk management is already considered an important topic and has prompted ample research on it. In public-private partnerships (PPPs), for example, some authors even assume that PPPs have more and a higher degree of risks than other projects because they involve many stakeholders, implicate complex project arrangements, may have special rules regarding financing, documentation and taxation, or lack in experienced partners (e.g., Carbonara et al. 2015; Grimsey and Lewis 2002; Wang et al. 2018). The situation in IUCs seems to be similar but while the PPP literature offers a huge number of articles investigating risks and risk management in such projects, the literature on IUCs rather ignores this aspect. This may either be because there is currently no application of risk management or because there is no research about it, or-most likelyboth. It is hard to tell why practitioners as well as researchers disregard this topic in such a way and we can only hypothesize the reasons as to why this is. Possibly, it is due to the good faith in universities and their reputation as reliable partners, but given the resources invested in such collaborations and the difficulties involved in bringing them to successful conclusion, both the financial and non-financial risks as well as the procedures put in place to manage them appear a subject worthy of investigation.

\section{Conclusion}

IUCs are increasingly important and it is in the interests of governments, policymakers, researchers and practitioners that such collaborations are successfully implemented. While the advantages and potential of these collaborations are well recognized, there are at the same time numerous hindrances and challenges to be met, which can lead to failure. In this review article, we identify factors that influence the success of an IUC and derive recommendations from the literature for a successful realization and implementation of such a partnership. These insights will help to establish fruitful collaborations between these two very different types of organizations.

We draw on the insights gained from reviewing the literature to identify potential issues that are hinted at in the works reviewed but not researched in depth. These gaps 
provide potential for future research. In particular, we identified four moderators that appear to interfere with influencing factors we derived from the literature. The actual impact of these moderators is as yet unclear. Future research should investigate whether and how the phase of a collaboration project, the scale of the partners, the organizational level or the scientific discipline interact with the main factors of influence. We also discuss implications for practitioners and propose a main recommendation for each category of our conceptual model. For the institutional factors we advise flexibility, for the relationship factors, honesty, for the output factors we advise clarity and for the framework factors, awareness. The conceptual model that we have proposed should serve as a useful framework for discussions among practitioners as well as for researchers.

Methodological choices always result from a weighing of advantages and drawbacks. To conclude, we briefly discuss limitations of our study that result from these choices. First, the process of literature selection involves certain limitations. Some relevant articles might be excluded due to the formulated definitions of the exclusion criteria, others remain undiscovered due to the selection of our search terms (for example, we did not search for 'higher education') and still others were not included because of the determined time frame. Second, although we conducted a systematic review of literature to minimize any bias and to ensure the replicability of the investigation, a certain degree of professional judgment cannot be eliminated within a review of social science literature (Denyer and Tranfield 2009). The development of our conceptual model, the definition and categorization of the factors or the assessment of the importance of certain factors is subject to fundamental decisions. Although, our decisions were guided by methodological considerations and recommendations of previous research or by the synopsis of our quantitative and qualitative syntheses of the reviewed papers, we still have to acknowledge that other judges might have drawn different conclusions or might have rated some aspects differently (inter-rater reliability). Finally, we only selected papers that explicitly considered the success of IUC, many of which did not address the reason the IUC was entered into originally. Following from this choice, we accepted the original papers' definition of success in the context of IUCs rather than imposing a homogeneous definition of success across studies. While this ensures upholding the fit of the original studies' aims and methods (a key quality criterion of research identified, e.g., by Boaz and Ashby 2003), it does not address any selection bias stemming from the fact that certain factors may influence both the propensity to start an IUC and its subsequent success.

Acknowledgements Open access funding provided by University of Graz.

Open Access This article is distributed under the terms of the Creative Commons Attribution 4.0 International License (http://creativecommons.org/licenses/by/4.0/), which permits unrestricted use, distribution, and reproduction in any medium, provided you give appropriate credit to the original author(s) and the source, provide a link to the Creative Commons license, and indicate if changes were made.

\section{Appendix}

See Table 1. 
Table 1 List of journals and their impact factor (IF)

\section{Journal title}

IF (2016)

No. of articles

Authors (years)

Research Policy

4.495

Arvanitis et al. (2008), Baba et al. (2009), Bodas Freitas et al. (2013b), Bruneel et al. (2010), Hong and Su (2013), Maietta (2015), Perkmann and Schildt (2015) Scandura (2016), Youtie et al. (2017)

$R \& D$ Management

Bayona Sáez et al. (2002), Galan-Muros and Plewa (2016), Fernandes and Ferreira (2013), Lee (2011), Perkmann et al. (2011)

International Journal of Innovation Management

Baba et al. (2010), Hadjimanolis (2006), Karlson and

Callagher (2012), Pinheiro et al. (2015b)

Journal of Product Innovation Management

Bstieler et al. (2015), Sherwood and Covin (2008),

Wirsich et al. (2016)

Management Decision

Henderson et al. (2006), Ryan (2007), Ryan (2009)

Small Business Economics

Calcagnini et al. (2016), Goel et al. (2017), Wang and Shapira (2012)

Technology Analysis and Strategic Management

Guan et al. (2005), Lai and Lu (2016), Lee et al. (2010)

Technovation

Hemmert et al. (2014), Petruzzelli (2011), Rajalo and Vadi (2017)

IEEE Transactions on Engineering Management

Santoro and Bierly (2006), Santoro and Saparito (2003)

Industrial Marketing Management

Canhoto et al. (2016), Clauss and Kesting (2017)

Industry and Innovation

Ferru (2010), Muscio and Vallanti (2014)

International Journal of Technology Transfer and Com-

Indarti and Wahid (2013), Myoken (2013)

Journal of Business Research

Berbegal-Mirabent et al. (2015), Bstieler et al. (2017)

Journal of Business Venturing

George et al. (2002), Soh and Subramanian (2014)

Journal of Education and Work

Reeve and Gallacher (2005), Slotte and Tynjälä (2003)

Journal of Engineering and Technology Management

Franco and Haase (2015), Santoro and Gopalakrishnan (2000)

Journal of High Technology Management Research

Santoro (2000), Siegel et al. (2003)

Journal of Research Administration

0.000 
Table 1 (continued)

\begin{tabular}{lll}
\hline Journal title & IF (2016) & No. of articles \\
Authors (years) & & \\
\hline
\end{tabular}

Journal of Technology Management and Innovation

0.000

de Medeiros et al. (2012), Vega-Jurado et al. (2017)

MIT Sloan Management Review

Perkmann and Salter (2012), Pertruzé et al. (2010)

Papers in Regional Science

$1.272 \quad 2$

Isabel Maria et al. (2014), Muscio (2013)

Theoretical and Applied Economics

Dindire et al. (2011), Şerbănică (2011)

American Business Law Journal

Newberg and Dunn (2002)

Benchmarking: An International Journal

Peças and Henriques (2006)

Brussels Economic Review

Sellenthin (2011)

Cambridge Journal of Economics

Howells et al. (2012)

China Economic Review

Muscio et al. (2012)

Construction Economics and Building

$0.000 \quad 1$

Bröchner and Lagerqvist (2016)

Creativity and Innovation Management

Goduscheit and Knudsen (2015)

CURIE Journal

Nellickappilly and Maya (2009)

Decision Support Systems

Wang et al. (2017)

Development Southern Africa

Wedekind and Mutereko (2016)

Economic Development Quarterly

Banal-Estañol et al. (2013)

Economics of Innovation and New Technology

Boardman and Bozeman (2015)

Engineering Management Journal

Johnson and Johnston (2001)

European Management Journal

Barnes et al. (2002)

International Journal of Advanced Corporate Learning

0.000

Wu (2017)

International Journal of Industrial Organization

Veugelers and Cassiman (2005)

International Journal of Innovation and Technology

0.000

Management

Rao and Mulloth (2016)

International Journal of Innovation Management

0.000

Han and Almas (2016) 
Table 1 (continued)

\begin{tabular}{lll}
\hline Journal title & IF (2016) & No. of articles \\
Authors (years) & & \\
\hline
\end{tabular}

International Journal of Production Research

Flores et al. (2009)

International Journal of Technology Management 1.036

Rampersad (2015)

International Journal of Technology Management and

Sustainable Develop

Attia (2015)

International Journal of Technology, Policy and Man-

agement

Xu et al. (2014)

Journal of Business Management

Kozlinska (2012)

Journal of Business-to-Business Marketing

MingJi and Ping (2014)

Journal of Economic Geography

D'Este et al. (2012)

Journal of Evolutionary Economics

Bodas Freitas and Verspagen (2017)

Journal of Information Systems Education

Poston and Richardson (2011)

Journal of Manufacturing Systems

Rodriguez et al. (2005)

Journal of Marketing Theory and Practice

Baker et al. (2005)

Journal of Product and Brand Management

Logar et al. (2001)

$0.000 \quad 1$

Knowledge and Process Management

0.000

Hong et al. (2010)

Measuring Business Excellence

0.000

Piva and Rossi-Lamastra (2013)

Nonprofit Management and Leadership

Schaffer (2012)

Poznan University of Economics Review

Gawel (2014)

Production Planning and Control

Al-Ashaab et al. (2011)

Regional Studies

Drejer and Ostergaard (2017)

Research Technology Management

Starbuck (2001)

Scandinavian Journal of Management

Ankrah and AL-Tabbaa (2015)

Small Enterprise Research

Collier et al. (2011)

Social Studies of Science

Bychkova (2016) 
Table 1 (continued)

\begin{tabular}{llc}
\hline $\begin{array}{l}\text { Journal title } \\
\text { Authors (years) }\end{array}$ & IF (2016) & No. of articles \\
\hline $\begin{array}{l}\text { Supply Chain Management: An International Journal } \\
\text { Sohal (2013) }\end{array}$ & 4.072 & 1 \\
$\begin{array}{l}\text { Total Quality Management and Business Excellence } \\
\text { Mashhadi et al. (2014) }\end{array}$ & 1.368 & 1 \\
Total & & 103 \\
\hline
\end{tabular}

\section{References}

Al-Ashaab A, Flores M, Doultsinou A, Magyar A (2011) A balanced scorecard for measuring the impact of industry-university collaboration. Prod Plan Control 22:554-570. https://doi.org/10.1080/09537 287.2010.536626

Ankrah S, AL-Tabbaa O (2015) Universities-industry collaboration: a systematic review. Scand J Manag 31:387-408. https://doi.org/10.1016/j.scaman.2015.02.003

Arvanitis S, Kubli U, Woerter M (2008) University-industry knowledge and technology transfer in Switzerland: what university scientists think about co-operation with private enterprises. Res Policy 37:1865-1883. https://doi.org/10.1016/j.respol.2008.07.005

Attia AM (2015) National innovation systems in developing countries: barriers to university-industry collaboration in Egypt. Int J Technol Manage Sustain Dev 14:113-124. https://doi.org/10.1386/ tmsd.14.2.113_1

Baba Y, Shichijo N, Sedita SR (2009) How do collaborations with universities affect firms' innovative performance? The role of 'Pasteur scientists' in the advanced materials field. Res Policy 38:756764. https://doi.org/10.1016/j.respol.2009.01.006

Baba Y, Yarime M, Shichijo N (2010) Sources of success in advanced materials innovation: the role of "core researchers" in university-industry collaboration in Japan. Int J Innov Manag 14:201-219. https://doi.org/10.1142/s1363919610002611

Baker SM, Faircloth JB, Simental V (2005) Perceptions of university-corporate partnership influences on a brand. J Mark Theory Pract 13:32-46. https://doi.org/10.1080/10696679.2005.11658542

Banal-Estañol A, Macho-Stadler I, Pérez-Castrillo D (2013) Research output from university-industry collaborative projects. Econ Dev Q 27:71-81. https://doi.org/10.1177/0891242412472535

Barnes T, Pashby I, Gibbons A (2002) Effective university-industry interaction: a multi-case evaluation of collaborative R\&D projects. Eur Manag J 20:272-285. https://doi.org/10.1016/s0263 -2373(02)00044-0

Bayona Sáez C, García Marco T, Huerta Arribas E, Bayona Saez C, Garc'ia Marco T (2002) Collaboration in R\&D with universities and research centres: an empirical study of Spanish firms. R D Manag 32:321-341. https://doi.org/10.1111/1467-9310.00264

Bergner S, Neubauer AC, Kreuzthaler A (2010) Broad and narrow personality traits for predicting managerial success. Eur J Work Organ Psychol 19:177-199. https://doi.org/10.1080/135943209028197 28

Bekkers R, Bodas Freitas IM (2008) Analysing knowledge transfer channels between universities and industry: to what degree do sectors also matter? Res Policy 37:1837-1853. https://doi. org/10.1016/j.respol.2008.07.007

Berbegal-Mirabent J, Sánchez García JL, Ribeiro-Soriano DE (2015) University-industry partnerships for the provision of R\&D services. J Bus Res 68:1407-1413. https://doi.org/10.1016/j.jbusr es.2015.01.023

Boardman C, Bozeman B (2015) Academic faculty as intellectual property in university-industry research alliances. Econ Innov New Technol 24:403-420. https://doi.org/10.1080/10438599.2014.988499

Boaz A, Ashby D (2003) Fit for purpose? Assessing research quality for evidence based policy and practice. Working Paper series of the ESRC No. 11. ESRC UK Centre for Evidence Based Policy and Practice, Queen Mary University, London 
Bodas Freitas IM, Verspagen B (2017) The motivations, institutions and organization of universityindustry collaborations in the Netherlands. J Evol Econ 27:379-412. https://doi.org/10.1007/s0019 1-017-0495-7

Bodas Freitas IM, Geuna A, Rossi F (2013a) Finding the right partners: institutional and personal modes of governance of university-industry interactions. Res Policy 42:50-62. https://doi.org/10.1016/j. respol.2012.06.007

Bodas Freitas IM, Marques RA, de Paula e Silva EM (2013b) University-industry collaboration and innovation in emergent and mature industries in new industrialized countries. Res Policy 42:443453. https://doi.org/10.1016/j.respol.2012.06.006

Borgia D, Bonvillian G, Rubens A (2011) Case study of Chinese and US University, college of business partnerships: form, process, opportunities, and challenges. J Manage Policy Pract 12:98-107

Bröchner J, Lagerqvist O (2016) From ideas to construction innovations: firms and universities collaborating. Constr Econ Build 16:76-89. https://doi.org/10.5130/ajceb.v16i1.4668

Bruneel J, D'Este P, Salter A (2010) Investigating the factors that diminish the barriers to universityindustry collaboration. Res Policy 39:858-868. https://doi.org/10.1016/j.respol.2010.03.006

Bryson JM, Crosby BC, Stone MM (2006) The design and implementation of cross-sector collaborations: propositions from the literature. Public Adm Rev 66:44-55. https://doi.org/10.111 1/j.1540-6210.2006.00665.x

Bstieler L, Hemmert M, Barczak G (2015) Trust formation in university-industry collaborations in the US biotechnology industry: IP policies, shared governance, and champions. J Prod Innov Manag 32:111-121. https://doi.org/10.1111/jpim.12242

Bstieler L, Hemmert M, Barczak G (2017) The changing bases of mutual trust formation in inter-organizational relationships: a dyadic study of university-industry research collaborations. J Bus Res 74:47-54. https://doi.org/10.1016/j.jbusres.2017.01.006

Bychkova O (2016) Innovation by coercion: emerging institutionalization of university-industry collaborations in Russia. Soc Stud Sci 46:511-535. https://doi.org/10.1177/0306312716654768

Calcagnini G, Giombini G, Liberati P, Travaglini G (2016) A matching model of university-industry collaborations. Small Bus Econ 46:31-43. https://doi.org/10.1007/s11187-015-9672-y

Canhoto AI, Quinton S, Jackson P, Dibb S (2016) The co-production of value in digital, universityindustry R\&D collaborative projects. Ind Mark Manag 56:86-96. https://doi.org/10.1016/j.indma rman.2016.03.010

Carbonara N, Costantino N, Gunnigan L, Pellegrino R (2015) Risk management in motorway PPP projects: empirical-based guidelines. Transp Rev 35:162-182. https://doi.org/10.1080/01441 647.2015.1012696

Clark B (2001) The entrepreneurial university: new foundations for collegiality, autonomy, and achievement. J Program Inst Manag High Educ 13:9-24

Clauss T, Kesting T (2017) How businesses should govern knowledge-intensive collaborations with universities: an empirical investigation of university professors. Ind Mark Manag 62:185-198. https:// doi.org/10.1016/j.indmarman.2016.09.001

Collier A, Gray BJ, Ahn MJ (2011) Enablers and barriers to university and high technology SME partnerships. Small Enterp Res 18:2-18. https://doi.org/10.5172/ser.18.1.2

Cummings JN, Kiesler S (2007) Coordination costs and project outcomes in multi-university collaborations. Res Policy 36:1620-1634. https://doi.org/10.1016/j.respol.2007.09.001

D'Este P, Guy F, Iammarino S (2012) Shaping the formation of university-industry research collaborations: what type of proximity does really matter? J Econ Geogr. https://doi.org/10.1093/jeg/lbs010

de Medeiros Rocha M, Brito Alves Lima G, Lameira VdJ, Gonçalves Quelhas OL (2012) Innovation as a critical success factor: an exploratory study about the partnership among university with pharmaceutical industry in Brazil. J Technol Manag Innov 7:148-160

Denyer D, Tranfield D (2009) Producing a systematic review. In: Buchanan DA, Bryman A (eds) The Sage handbook of organizational research methods. Sage Publ, Los Angeles

Dindire L, Asandei M, Ganescu C (2011) Enhancement of cooperation and communication between universities and the business environment, requirement for a good functioning of the knowledge triangle: education, research, innovation. Theor Appl Econ 18:89-102

Drejer I, Ostergaard CR (2017) Exploring determinants of firms' collaboration with specific universities: employee-driven relations and geographical proximity. Reg Stud 51:1192-1205. https://doi. org/10.1080/00343404.2017.1281389

EBSCO (2016) Academic search premier: magazines and journals. https://www.ebscohost.com/titleLists/ aph-journals.pdf. Accessed 7 December 2016 
Etzkowitz H (2003) Research groups as 'quasi-firms': the invention of the entrepreneurial university. Res Policy 32:109-121. https://doi.org/10.1016/s0048-7333(02)00009-4

Etzkowitz H, Leydesdorff L (2000) The dynamics of innovation: from national systems and "Mode 2" to a Triple Helix of university-industry-government relations. Res Policy 29:109-123. https://doi. org/10.1016/s0048-7333(99)00055-4

Fernandes CI, Ferreira JJM (2013) Knowledge spillovers: cooperation between universities and KIBS. R D Manag 43:461-472. https://doi.org/10.1111/radm.12024

Ferru M (2010) Formation process and geography of science-industry partnerships: the case of the University of Poitiers. Ind Innov 17:531-549. https://doi.org/10.1080/13662716.2010.509998

Flores M, Boër C, Huber C, Plüss A, Schoch R, Pouly M (2009) Universities as key enablers to develop new collaborative environments for innovation: successful experiences from Switzerland and India. Int J Prod Res 47:4935-4953. https://doi.org/10.1080/00207540902847454

Franco M, Haase H (2015) University-industry cooperation: researchers' motivations and interaction channels. J Eng Technol Manag 36:41-51. https://doi.org/10.1016/j.jengtecman.2015.05.002

Galan-Muros V, Plewa C (2016) What drives and inhibits university-business cooperation in Europe? A comprehensive assessement. R D Manag 46:369-382. https://doi.org/10.1111/radm.12180

Gawel A (2014) Business collaboration with universities as an example of corporate social responsibility: a review of case study collaboration methods. Pozn Univ Economics Rev 14:20-30

George G, Zahra SA, Wood DR (2002) The effects of business-university alliances on innovative output and financial performance: a study of publicly traded biotechnology companies. J Bus Ventur 17:577-609

Gibbons M, Limoges C, Nowotny H, Schwartzman S, Scott P, Trow M (2002) The new production of knowledge: The dynamics of science and research in contemporary science, 7th edn. SAGE Publications, London

Goduscheit RC, Knudsen MP (2015) How barriers to collaboration prevent progress in demand for knowledge: a dyadic study of small and medium-sized firms, research and technology organizations and universities. Creat Innov Manag 24:29-54. https://doi.org/10.1111/caim.12101

Goel R, Göktepe-Hulten D, Grimpe C (2017) Who instigates university-industry collaborations? University scientists versus firm employees. Small Bus Econ 48:503-524. https://doi.org/10.1007/s1118 7-016-9795-9

Grimsey D, Lewis MK (2002) Evaluating the risks of public private partnerships for infrastructure projects. Int J Project Manag 20:107-118

Guan JC, Yam RCM, Mok CK (2005) Collaboration between industry and research institutes/universities on industrial innovation in Beijing, China. Technol Anal Strateg Manag 17:339-353. https://doi. org/10.1080/09537320500211466

Hadjimanolis A (2006) A case study of SME-university research collaboration in the context of a small peripheral country (Cyprus). Int J Innov Manag 10:65-88

Han J, Almas H (2016) Determinants of financial rewards from industry-university collaboration in South Korea. Int J Innov Manag 20:1-26. https://doi.org/10.1142/s1363919616500754

Hemmert M, Bstieler L, Okamuro H (2014) Bridging the cultural divide: trust formation in universityindustry research collaborations in the US, Japan, and South Korea. Technovation 34:605-616. https://doi.org/10.1016/j.technovation.2014.04.006

Henderson J, McAdam R, Leonard D (2006) Reflecting on a TQM-based university/industry partnership: contributions to research methodology and organisational learning. Manag Decis 44:1422-1440. https://doi.org/10.1108/00251740610715731

Hillebrand B, Biemans WG (2003) The relationship between internal and external cooperation. J Bus Res 56:735-743. https://doi.org/10.1016/s0148-2963(01)00258-2

Hong W, Su Y-S (2013) The effect of institutional proximity in non-local university-industry collaborations: an analysis based on Chinese patent data. Res Policy 42:454-464. https://doi.org/10.1016/j. respol.2012.05.012

Hong J, Heikkinen J, Blomqvist K (2010) Culture and knowledge co-creation in R\&D collaboration between MNCs and Chinese universities. Knowl Process Manag 17:62-73. https://doi.org/10.1002/ kpm. 342

Howells J, Ramlogan R, Cheng S-L (2012) Innovation and university collaboration: paradox and complexity within the knowledge economy. Camb J Econ 36:703-721. https://doi.org/10.1093/cje/ bes013 
Indarti N, Wahid F (2013) How do Indonesian industries perceive university-industry collaboration? Motivations, benefits and problems. Int J Technol Trans Commer 12:157-171. https://doi. org/10.1504/ijttc.2013.064169

International organization for standardization (2018) ISO 31000: Risk management—guidelines. https:// www.iso.org/obp/ui/\#iso:std:iso:31000:ed-2:v1:en. Accessed 20 Aug 2018

Isabel Maria BF, Rossi F, Geuna A (2014) Collaboration objectives and the location of the university partner: evidence from the Piedmont region in Italy. Pap Reg Sci 93:203-226. https://doi. org/10.1111/pirs.12054

Johnson WHA, Johnston DA (2001) Aligning technical and business goals in industry-university collaborative R\&D projects: a tale of two projects. Eng Manag J 13:23-27. https://doi.org/10.1080/10429 247.2001.11415102

Karlson B, Callagher L (2012) Which university to partner with: an investigation into partner selection motives among small innovative firms. Int J Innov Manag 16:1-16. https://doi.org/10.1142/s1363 919612400026

Kozlinska I (2012) Obstacles to university-industry cooperation in the domain of entrepreneurship. J Bus Manag 6:153-160

Lai IKW, Lu T-W (2016) How to improve the university-industry collaboration in Taiwan's animation industry? Academic vs. industrial perspectives. Technol Anal Strateg Manag 28:717-732. https:// doi.org/10.1080/09537325.2016.1141404

Lee K-J (2011) From interpersonal networks to inter-organizational alliances for university-industry collaborations in Japan: the case of the Tokyo Institute of Technology. R D Manag 41:190-201. https ://doi.org/10.1111/j.1467-9310.2011.00633.x

Lee K-J, Ohta T, Kakehi K (2010) Formal boundary spanning by industry liaison offices and the changing pattern of university-industry cooperative research: the case of the University of Tokyo. Technol Anal Strateg Manag 22:189-206. https://doi.org/10.1080/09537320903498538

Leisytë L, Kizniene D (2006) New public management in Lithuania's higher education. High Educ Policy 19:377-396. https://doi.org/10.1057/palgrave.hep.8300122

Logar CM, Ponzurick TG, Spears JR, Russo France K (2001) Commercializing intellectual property: a university-industry alliance for new product development. J Prod Brand Manag 10:206-217. https ://doi.org/10.1108/eum0000000005672

Maietta OW (2015) Determinants of university-firm R\&D collaboration and its impact on innovation: a perspective from a low-tech industry. Res Policy 44:1341-1359. https://doi.org/10.1016/j.respo 1.2015.03.006

Marhl M, Pausits A (2011) Third mission indicators for new ranking methodologies. Eval High Educ 5:43-64

Mashhadi AF, Alänge S, Roos L-U (2014) A learning alliance for robust design in product development: the case of Volvo 3P and Chalmers University of Technology. Total Qual Manag Bus Excell 25:1054-1071. https://doi.org/10.1080/14783363.2013.807680

Mattessich PW, Murray-Close M, Monsey BR (2004) Collaboration: What makes it work, 2nd edn. Amherst H. Wilder Foundation, Saint Paul Minn

MingJi J, Ping Z (2014) Research on the patent innovation performance of university-industry collaboration based on complex network analysis. J Bus Bus Mark 21:65-83. https://doi.org/10.1080/10517 12x.2014.903454

Mowday RT, Steers RM, Porter LW (1979) The measurement of organizational commitment. J Vocat Behav 14:224-247. https://doi.org/10.1016/0001-8791(79)90072-1

Muscio A (2013) University-industry linkages: what are the determinants of distance in collaborations? Pap Reg Sci 92:715-739. https://doi.org/10.1111/j.1435-5957.2012.00442.x

Muscio A, Vallanti G (2014) Perceived obstacles to university-industry collaboration: results from a qualitative survey of Italian academic departments. Ind Innov 21:410-429. https://doi. org/10.1080/13662716.2014.969935

Muscio A, Quaglione D, Scarpinato M (2012) The effects of universities' proximity to industrial districts on university-industry collaboration. China Econ Rev 23:639-650. https://doi.org/10.1016/j.chiec o.2011.07.001

Myoken Y (2013) The role of geographical proximity in university and industry collaboration: case study of Japanese companies in the UK. Int J Technol Trans Commer 12:43-61. https://doi.org/10.1504/ ijttc.2013.064170

Nellickappilly S, Maya KG (2009) Industry-university collaboration: some ethical considerations. CURIE Journal 2:5-14 
Newberg JA, Dunn RL (2002) Keeping secrets in the campus lab: law, values and rules of engagement for industry-university R\&D partnerships. Am Bus Law J 39:187-240. https://doi. org/10.1111/j.1744-1714.2002.tb00298.x

Niedergassel B, Leker J (2011) Different dimensions of knowledge in cooperative R\&D projects of university scientists. Technovation 31:142-150. https://doi.org/10.1016/j.technovation.2010.10.005

OECD (2015) OECD science, technology and industry scoreboard 2015: innovation for growth and society. OECD, Paris

OECD (2017) State of higher education 2015-16. OECD Higher Education Programme, Paris

Parkhe A (1993) Strategic alliance structuring: a game theoretic and transaction cost examination of interfirm cooperation. Acad Manag J 36:794-829. https://doi.org/10.2307/256759

Pawson R (2006) Evidence-based policy: a realist perspective. SAGE, London

Peças P, Henriques E (2006) Best practices of collaboration between university and industrial SMEs. Benchmark Int J 13:54-67. https://doi.org/10.1108/14635770610644574

Perkmann M, Salter A (2012) How to create productive partnerships with universities. MIT Sloan Manag Rev 53:79-88

Perkmann M, Schildt H (2015) Open data partnerships between firms and universities: the role of boundary organizations. Res Policy 44:1133-1143. https://doi.org/10.1016/j.respol.2014.12.006

Perkmann M, Neely A, Walsh K (2011) How should firms evaluate success in university-industry alliances?: a performance measurement system. R D Manag 41:202-216. https://doi.org/10.111 $1 / \mathrm{j} .1467-9310.2011 .00637 . x$

Perkmann M, Tartari V, McKelvey M, Autio E, Broström A, D’Este P, Fini R, Geuna A, Grimaldi R, Hughes A, Krabel S, Kitson M, Llerena P, Lissoni F, Salter A, Sobrero M (2013) Academic engagement and commercialisation: a review of the literature on university-industry relations. Res Policy 42:423-442. https://doi.org/10.1016/j.respol.2012.09.007

Pertruzé JA, Calder ES, Greitzer EM, Lucas WA (2010) Best practices for industry-university collaboration. MIT Sloan Manag Rev 51:83-90

Petruzzelli AM (2011) The impact of technological relatedness, prior ties, and geographical distance on university-industry collaborations: a joint-patent analysis. Technovation 31:309-319. https://doi. org/10.1016/j.technovation.2011.01.008

Pfeffer J (1981) Power in organizations. Pitman Publishing Corp, Marshfield

Philbin SP (2010) Developing and managing university-industry research collaborations through a process methodology/industrial sector approach. J Res Admin 41:51-68

Pinheiro R, Langa PV, Pausits A (2015a) One and two equals three?: The third mission of higher education institutions. Eur J High Educ 5:233-249. https://doi.org/10.1080/21568235.2015.1044552

Pinheiro ML, Lucas C, Pinho JC (2015b) Social network analysis as a new methodological tool to understand university-industry cooperation. Int J Innov Manag 19:1550013. https://doi.org/10.1142/ s1363919615500139

Piva E, Rossi-Lamastra C (2013) Systems of indicators to evaluate the performance of university-industry alliances: a review of the literature and directions for future research. Meas Bus Excell 17:4054. https://doi.org/10.1108/mbe-01-2013-0004

Plewa C, Korff N, Johnson C, Macpherson G, Baaken T, Rampersad GC (2013a) The evolution of university-industry linkages: a framework. J Eng Technol Manage 30:21-44. https://doi.org/10.1016/j. jengtecman.2012.11.005

Plewa C, Korff N, Baaken T, Macpherson G (2013b) University-industry linkage evolution: an empirical investigation of relational success factors. R D Manag 43:365-380. https://doi.org/10.1111/ radm. 12021

Porter LW, Smith FJ (1970) The etiology of organizational commitment. Unpublished manuscript. University of California, Irvine

Poston RS, Richardson SM (2011) Designing an academic project management program: a collaboration between a university and a PMI chapter. J Inf Syst Educ 22:55-72

Rajalo S, Vadi M (2017) University-industry innovation collaboration: reconceptualization. Technovation 62-63:42-54. https://doi.org/10.1016/j.technovation.2017.04.003

Rampersad GC (2015) Developing university-business cooperation through work-integrated learning. Int J Technol Manag 68:203-227. https://doi.org/10.1504/ijtm.2015.069664

Rao B, Mulloth B (2016) The Role of universities in encouraging growth of technology-based new ventures. Int J Innov Technol Manag 14:1-22. https://doi.org/10.1142/s0219877017500146

Reeve F, Gallacher J (2005) Employer-university 'partnerships': a key problem for work-based learning programmes? J Educ Work 18:219-233. https://doi.org/10.1080/13639080500085992 
Rodriguez CA, de Giurana J, Elías A (2005) Industry and university cooperation to enhance manufacturing education. J Manuf Syst 24:277-287. https://doi.org/10.1016/s0278-6125(06)80019-1

Ryan L (2007) Developing a qualitative understanding of university-corporate education partnerships. Manag Decis 45:153-160. https://doi.org/10.1108/00251740710727214

Ryan L (2009) Exploring the growing phenomenon of university-corporate education partnerships. Manag Decis 47:1313-1322. https://doi.org/10.1108/00251740910984569

Santoro MD (2000) Success breeds success: the linkage between relationship intensity and tangible outcomes in industry-university collaborative ventures. J High Technol Manag Res 11:255-273. https ://doi.org/10.1016/s1047-8310(00)00032-8

Santoro MD, Bierly PE (2006) Facilitators of knowledge transfer in university-industry collaborations: a knowledge-based perspective. IEEE Trans Eng Manag 53:495-507. https://doi.org/10.1109/ tem.2006.883707

Santoro MD, Chakrabarti AK (2002) Firm size and technology centrality in industry-university interactions. Res Policy 31:1163-1180. https://doi.org/10.1016/s0048-7333(01)00190-1

Santoro MD, Gopalakrishnan S (2000) The institutionalization of knowledge transfer activities within industry-university collaborative ventures. J Eng Technol Manag 17:299-319. https://oi. org/10.1016/s0923-4748(00)00027-8

Santoro MD, Saparito PA (2003) The firm's trust in its university partner as a key mediator in advancing knowledge and new technologies. IEEE Trans Eng Manag 50:362-373. https://doi.org/10.1109/ tem.2003.817287

Scandura A (2016) University-industry collaboration and firms' R\&D effort. Res Policy 45:1907-1922. https://doi.org/10.1016/j.respol.2016.06.009

Schaffer RH (2012) Nonprofit and university strategic partnerships to strengthen the sector. Nonprofit Manag Leadersh 23:105-119. https://doi.org/10.1002/nml.21057

Schein EH (2004) Organizational culture and leadership, 3rd edn. Jossey-Bass, San Francisco

Schofield T (2013) Critical success factors for knowledge transfer collaborations between university and industry. J Res Admin 44:38-56

Sellenthin MO (2011) Factors that impact on university-industry collaboration: empirical evidence from Sweden and Germany. Bruss Econ Rev 54:81-100

Şerbănică C (2011) A cause and effect analysis of university: business cooperation for regional innovation in Romania. Theo Appl Econ 18:29-44

Sherwood AL, Covin JG (2008) Knowledge acquisition in university-industry alliances: an empirical investigation from a learning theory perspective. J Prod Innov Manag 25:162-179. https://doi.org/1 0.1111/j.1540-5885.2008.00292.x

Siegel DS, Waldman DA, Atwater LE, Link AN (2003) Commercial knowledge transfers from universities to firms: improving the effectiveness of university-industry collaboration. J High Technol Manag Res 14:111-133. https://doi.org/10.1016/s1047-8310(03)00007-5

Slotte V, Tynjälä P (2003) Industry-university collaboration for continuing professional development. J Educ Work 16:445-464. https://doi.org/10.1080/1363908032000093058

Soh P-H, Subramanian AM (2014) When do firms benefit from university-industry R\&D collaborations? The implications of firm R\&D focus on scientific research and technological recombination. J Bus Ventur 29:807-821. https://doi.org/10.1016/j.jbusvent.2013.11.001

Sohal AS (2013) Developing competencies of supply chain professionals in Australia: collaboration between businesses, universities and industry associations. Supply Chain Manag 18:429-439. https ://doi.org/10.1108/scm-07-2012-0228

Starbuck E (2001) Optimizing university research collaborations. Res Technol Manag 44:40-44

Tranfield D, Denyer D, Smart P (2003) Towards a methodology for developing evidence-informed management knowledge by means of systematic review. Br J Manag 14:207-222. https://doi. org/10.1111/1467-8551.00375

Vega-Jurado J, Kask S, Manjarres-Henriquez L (2017) University industry links and product innovation: cooperate or contract? J of Technol Manag Innov 12:1-8

Veugelers R, Cassiman B (2005) R\&D cooperation between firms and universities: some empirical evidence from Belgian manufacturing. Int J Ind Organ 23:355-379. https://doi.org/10.1016/j.ijind org.2005.01.008

Wang J, Shapira P (2012) Partnering with universities: a good choice for nanotechnology start-up firms? Small Bus Econ 38:197-215. https://doi.org/10.1007/s11187-009-9248-9 
Wang Q, Ma J, Liao X, Du W (2017) A context-aware researcher recommendation system for universityindustry collaboration on R\&D projects. Decis Support Syst 103:46-57. https://doi.org/10.1016/j. dss.2017.09.001

Wang H, Xiong W, Wu G, Zhu D (2018) Public-private partnership in Public Administration discipline: a literature review. Public Manag Rev 20:293-316. https://doi.org/10.1080/14719037.2017.13134 45

Wedekind V, Mutereko S (2016) Higher education responsiveness through partnerships with industry: the case of a university of technology programme. Dev South Afr 33:376-389. https://doi. org/10.1080/0376835x.2016.1156516

Wirsich A, Kock A, Strumann C, Schultz C (2016) Effects of university-industry collaboration on technological newness of firms. J Prod Innov Manag 33:708-725. https://doi.org/10.1111/jpim.12342

$\mathrm{Wu} \mathrm{H}$ (2017) The essentiality of sustainability and variety for industry collaborations with university partners. Int J Adv Corp Learn 10:19-29. https://doi.org/10.3991/ijac.v10i2.7272

Xu G, Zhou Y, Xu L, Li S (2014) Effects of control in open innovation: an empirical study of universityindustry cooperation in China. Int J Technol Policy Manag 14:346-363. https://doi.org/10.1504/ ijtpm.2014.065010

Youtie J, Li Y, Rogers J, Shapira P (2017) Institutionalization of international university research ventures. Res Policy 46:1692-1705. https://doi.org/10.1016/j.respol.2017.08.006 